\title{
Blood cleaner on-chip design for artificial human kidney manipulation
}

This article was published in the following Dove Press journal:

International Journal of Nanomedicine

29 April 20II

Number of times this article has been viewed

\author{
N Suwanpayak' \\ MA Jalil ${ }^{2}$ \\ MS Aziz \\ FD Ismail $\left.\right|^{3}$ \\ $\mathrm{J} \mathrm{Ali}^{3}$ \\ PP Yupapin'
}

'Nanoscale Science and Engineering Research Alliance (N'SERA), Advanced Research Center for Photonics, Faculty of Science, King Mongkut's Institute of Technology, Ladkrabang, Bangkok, Thailand; ${ }^{2}$ lbnu Sina Institute of Fundamental Science Studies (IIS), ${ }^{3}$ Institute of Advanced Photonics Science, Nanotechnology Research Alliance, Universiti Teknologi Malaysia, Johor Bahru, Malaysia
Correspondence: PP Yupapin Nanoscale Science and Engineering Research Alliance (N'SERA), Advanced Research Center for Photonics, Faculty of Science, King Mongkut's Institute of Technology, Ladkrabang, Bangkok I0520, Thailand

Tel +66 23298414

Fax +6623298410

Email kypreech@kmitl.ac.th
Abstract: A novel design of a blood cleaner on-chip using an optical waveguide known as a PANDA ring resonator is proposed. By controlling some suitable parameters, the optical vortices (gradient optical fields/wells) can be generated and used to form the trapping tools in the same way as optical tweezers. In operation, the trapping force is formed by the combination between the gradient field and scattering photons by using the intense optical vortices generated within the PANDA ring resonator. This can be used for blood waste trapping and moves dynamically within the blood cleaner on-chip system (artificial kidney), and is performed within the wavelength routers. Finally, the blood quality test is exploited by the external probe before sending to the destination. The advantage of the proposed kidney on-chip system is that the unwanted substances can be trapped and filtered from the artificial kidney, which can be available for blood cleaning applications.

Keywords: optical trapping, blood dialysis, blood cleaner, human kidney manipulation

\section{Introduction}

Human kidneys are important excretory organs whose main functions are maintaining the concentrations of various ions and other important substances constant, and the removal of wastes and other unwanted substances in the urine. ${ }^{1}$ One living human kidney has from 300,000 to over 1,000,000 nephrons, ${ }^{2}$ the number of which is related to birth weights. ${ }^{3}$ Each nephron comprises two parts, namely the glomerulus and the tubules. The glomerulus is comprised of capillary vessels and the blood plasma is filtered from the blood through the porous wall of the vessels. ${ }^{1}$

Chronic kidney disease (CKD) is a worldwide health problem increasing dramatically in several countries. ${ }^{4,5}$ This is a key focus for health care planning, even in the developed world, in which many clinical organizations have been established for the development of hemodialysis devices and methods. ${ }^{6-8} \mathrm{CKD}$ and acute renal failure occurs when one suffers from gradual and usually permanent loss of kidney function over time and loses the ability to filter and remove waste and extra fluids from the body.

Hemodialysis is the process of removing waste products from the blood. This removal is normally done by the kidneys. If they are impaired and require treatment, ${ }^{9}$ a dialysis machine (artificial kidney) can perform a similar function. The invention, manufacture, and implantation of the artificial kidney has been developed from the human organ. ${ }^{10-14}$ But artificial kidney dialysis has several disadvantages such as time wastage for blood dialysis (2-4 hours/visit), and the need for patients to visit the hospital every week (2-3 times/week). This has led researchers and inventors 
to develop an implantable artificial kidney, ${ }^{15}$ which would increase convenience.

Optical trapping was first invented by Ashkin. ${ }^{16}$ It emerged as a powerful tool with wide-reaching applications in biology, physics, engineering, and medicine. ${ }^{17}$ The ability of optical trapping and manipulation of viruses, living cells, and bacteria without organelle damage ${ }^{18}$ by laser radiation pressure has been demonstrated. ${ }^{19,20}$ This is specific to medicine and the application of nanotechnology. Lee et $\mathrm{al}^{21,22}$ carried out a single red blood cell (RBC) deformability test, which was performed by using optical trapping plastic in a microfluidics chip, and a lab-on-a-chip for RBC transportation in the capillary network to circulate oxygen and carbon dioxide throughout the human body. ${ }^{23}$ The optical trapping manipulation molecules in the liquid-core waveguide and its application to drug delivery has been reported by Suwanpayak et al, ${ }^{24}$ in which a PANDA ring resonator is used to form, transmit, and receive the microscopic volume of the drug by controlling the ring parameters. This microscopic volume can be trapped and transported dynamically within the wavelength router or network.

Recently, the promising technique of microscopic volume trapping and transportation within an add/drop multiplexer have been reported both in theory ${ }^{25}$ and experiment, ${ }^{26}$ respectively. Here the transporter is known as an optical tweezer. The optical tweezer generation technique is used as a powerful tool for the manipulation of micrometer-sized particles. To date, the usefulness of static tweezers is well recognized. Moreover, the use of dynamic tweezers is now also used in practical work. ${ }^{27-29}$ Schulz et $\mathrm{al}^{30}$ have shown the possibility of trapped atom transfer between two optical potentials. In principle, an optical tweezer uses the forces exerted by intensity gradients in the strongly focused beams of light to trap and move the microscopic volumes of matter by a combination of forces induced by the interaction between photons, due to the photon scattering effect. In application, the field intensity can be adjusted and tuned to the desired gradient field. The scattering force can then form the suitable trapping force. Hence, the appropriate force can be configured as the transmitter/receiver for performing long distance microscopic transportation.

In this paper, the dynamic optical tweezers/vortices are generated using dark soliton, bright soliton, and Gaussian pulse propagating within an add/drop optical multiplexer incorporating two nanoring resonators (PANDA ring resonator). The dynamical behavior of soliton and Gaussian pulse is well described by Tasakorn et al. ${ }^{31}$ By using the proposed system, the blood waste and unwanted substances can be trapped and transported (filtered) from the artificial human kidney. Here, the required trapping tool sizes can be generated and formed for the specific blood waste molecules, where finally the clean blood can be obtained and sent to the destination via the through port. However, in practice, several sensors are required for environmental and blood quality control, which will be the topic of future investigation.

\section{Theoretical background}

In theory, the trapping forces are exerted by the intensity gradients in the strongly focused beams of light to trap and move the microscopic volumes of matter, in which the optical forces are customarily defined by the relationship below. ${ }^{32}$

$$
F=\frac{Q n_{m} P}{c}
$$

Here, $Q$ is a dimensionless efficiency, $n_{m}$ is the refractive index of the suspending medium, $c$ is the speed of light, and $P$ is the incident laser power, measured using the specimen. $Q$ represents the fraction of power utilized to exert force. For plane waves incident on a perfectly absorbing particle, $Q$ is equal to 1 . To achieve stable trapping, the radiation pressure must create a stable, three-dimensional equilibrium. Because biological specimens are usually contained in an aqueous medium, the dependence of $F$ on $n_{m}$ can rarely be exploited to achieve higher trapping forces. Increasing the laser power is possible, but only over a limited range due to the possibility of optical damage. $Q$ itself is therefore the main determinant of trapping force. It depends upon the NA (numerical aperture), laser wavelength, light polarization state, laser mode structure, relative index of refraction, and the geometry of the particle.

Furthermore, in the Rayleigh regime, trapping forces decompose naturally into two components. Since the electromagnetic field is uniform across the dielectric, particles can be treated as induced point dipoles. The scattering force is given by: ${ }^{32}$

$$
F_{\text {scatt }}=n_{m} \frac{\langle S\rangle \sigma}{c}
$$

where

$$
\sigma=\frac{8}{3} \pi(k r)^{4} r^{2}\left(\frac{m^{2}-1}{m^{2}+2}\right)^{2}
$$

Here, $\sigma$ is the scattering cross section of a Rayleigh sphere with radius $r$. $\langle\mathrm{S}\rangle$ is the time averaged Poynting vector, $n$ is the index of refraction of the particle, $m=n / n_{m}$ is the relative index, and $k=2 \pi n_{m} / \lambda$ is the wavenumber of the light. 
The scattering force is proportional to the energy flux and points along the direction of the propagation of the incident light. The gradient field $\left(F_{\text {grad }}\right)$ is the Lorentz force acting on the dipole induced by the light field, and is given by: ${ }^{32}$

$$
F_{\text {grad }}=\frac{\alpha}{2} \nabla\left\langle E^{2}\right\rangle
$$

where

$$
\alpha=n_{m}^{2} r^{3}\left(\frac{m^{2}-1}{m^{2}+2}\right)
$$

is the polarizability of the particle. The gradient force is proportional and parallel to the gradient in energy density (for $m>1$ ). The large gradient force is formed by the large depth of the laser beam. The stable trapping requires that the gradient force is in the $-\check{Z}$ direction, which is against the direction of the incident light (dark soliton valley), and is greater than the scattering force. By increasing the NA, when the focal spot size is decreased, the gradient strength is increased. ${ }^{33}$ This happens within a tiny system, for instance, in nanoscale devices such as the nanoring resonator.

In our proposal, the trapping force is formed by using a dark soliton, in which the valley of the dark soliton is generated and controlled within the PANDA ring resonator by the control port signals. In operation, the optical tweezers can be trapped, transported, and stored within the PANDA ring resonator and wavelength router, which can be used to form the microscopic volume (molecule) transportation, thus allowing drug delivery via the waveguide. ${ }^{34}$ The manipulation of trapped microscopic volumes within the optical tweezers has been previously reported. ${ }^{25}$

\section{Kidney on-chip manipulation}

Microfluidics is a burgeoning field with important applications in areas such as medical devices, biotechnology, chemical synthesis, and analytical chemistry. ${ }^{34}$ The Erickson $1 a b^{35-40}$ research interests revolve around the study of micronanofluidics, including advancing flows, delivery, and implantable devices for living organs, in combination with optics. ${ }^{41-43}$ In this paper, we propose use of the optical trapping tools in the application of blood manipulation dialysis (kidney dialysis) using the PANDA ring resonator systems by incorporating a wavelength router. In the blood cleaner on-chip (Figure 1), we used the same theory of optical trapping and transportation technique for a blood dialysis system, in which the blood flows $\mathrm{s}^{44,45}$ into the input port of the PANDA ring resonator, where the PANDA ring resonator

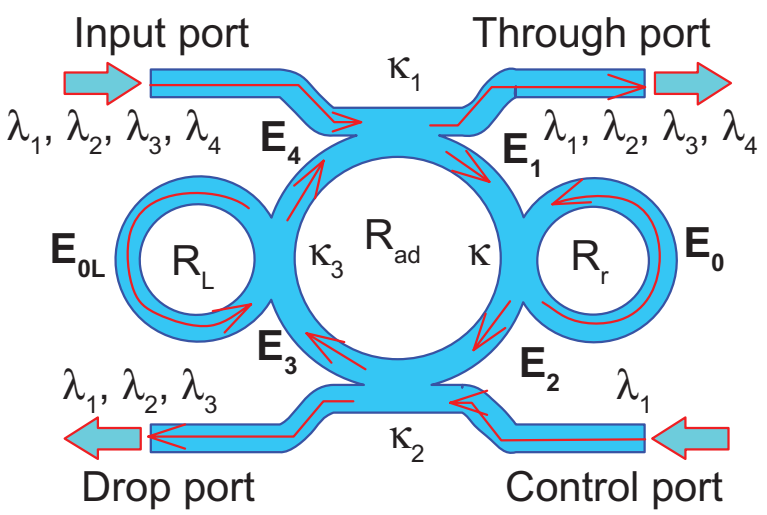

Figure I Schematic diagram of a proposed PANDA ring resonator.

system $1(\mathrm{P} 1)$ works the same way as PANDA ring resonator system 2 (P2). The whole blood volume can be trapped and delivered in liquid-core waveguide, ${ }^{46}$ of both high and low refractive indices, depending on the blood concentration, in which the whole blood concentration is $20 \%(n=1.35), 40 \%$ $(\mathrm{n}=1.35), 60 \%(\mathrm{n}=1.37) .{ }^{47,48}$

In operation, when blood flows in the waveguide channel, ${ }^{49,50}$ it is detected by a blood concentrate detector (versatile sensor, 3). ${ }^{51,52}$ Most important for blood dialysis is protein reabsorption into the renal artery, with the clean blood protein sensor ${ }^{53,54}$ placed to check the protein quality before release into the urine. The protein sensor will detect the blood protein component and help to regulate blood circulation until it is clean. Additionally, oxygen can be fed into the system via the add port (control) for high quality whole blood which is detected by wireless blood pressure ${ }^{55}$ before delivery into the renal artery. In this case, the filtrate components are sodium $(\sim 0.4 \mathrm{~nm})$, chlorine $(\sim 0.6 \mathrm{~nm})$, and glucose $(\sim 0.72 \mathrm{~nm}) .{ }^{56}$ Our system is integrated to be a single chip, which is equivalent to one Bowman's capsule consisting of the glomerulus build-up in the capillary vessels.

A schematic of a blood cleaner is as shown in Figure 2, which is formed by PANDA ring resonators and liquidcore waveguide as shown in Figure 3A. The waveguides were constructed by using different sizes and refractive indices as shown in Figure 3B, where in this case the blood cell index is 1.35 . The different waveguides with sizes of 5-8 $\mu \mathrm{m}$ and $1 \mathrm{~nm}$ were constructed for blood cells and proteins, respectively. The whole blood is input into the system via liquid-core 1 (input port), and the required trapping molecules can be trapped and filtered by liquid-core 2 . Finally, the unwanted substances are trapped and filtered via the drop ports. In Figure 2A, the whole blood cells are input into the blood cleaner via the input ports $\left(\mathrm{E}_{\text {in }}\right)$, which is equivalent to the blood flow into the afferent artery as 


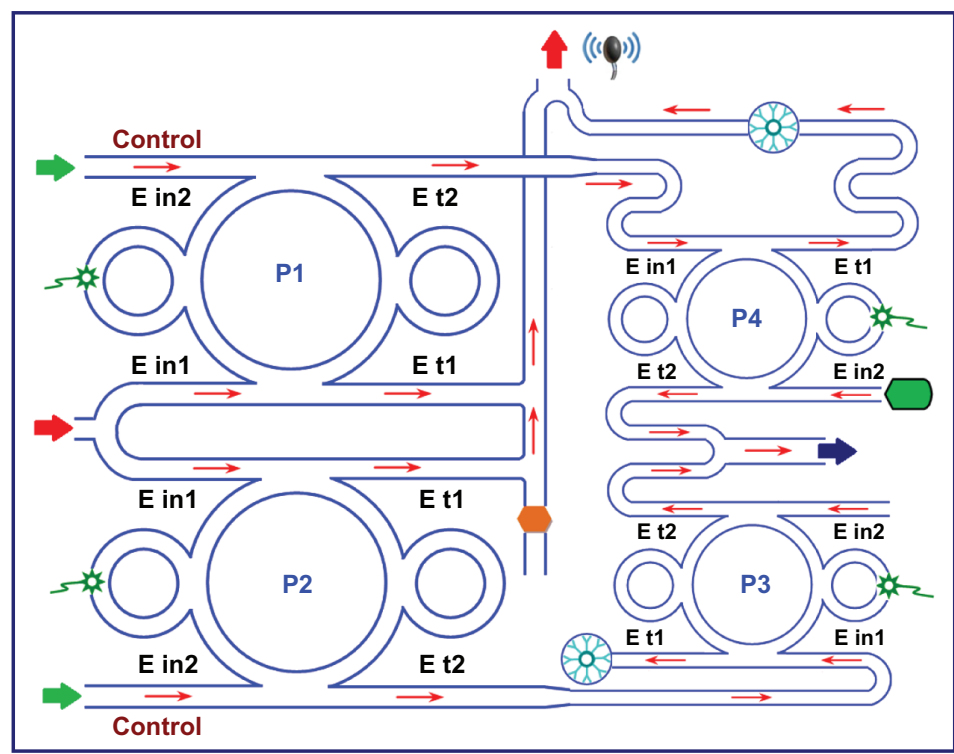

E in1: Input port

E t1 : Throughput port

E in2: Add port

E t2 : Drop port

$>$ (1) Blood in

t2 (2) Bio-sensor

(3) Versatile sensor

(4) Protein sensor

(5) Oxygen

(6) Urine

(7) Wireless blood

pressure sensor

(8) Clean blood

Figure 2 Schematic of an artificial kidney manipulation on-chip system.

shown in Figure 2B. After the blood waste substances are filtered by the glomerulus, they are filtrated via the proximal tube. Finally, the clean blood is received via the efferent artery. The blood artery is replaced by the blood waveguide structure, which is formed by the liquid-core waveguide as shown in Figure 3, where the red blood cells (RBCs) with 5-8 $\mu \mathrm{m}$ are input into the system via the input ports (liquid core 1), while the unwanted substances are trapped by the optical tweezers and filtered by the drop ports. Liquid core 2 is used for the trapped proteins, in which the protein molecule size is $1 \mathrm{~nm}$, which is smaller than the RBC, and therefore, the RCBs cannot be transported via the liquid-cores, which means only the unwanted substances are being trapped and transported in the liquid-core 2.

To form the optical trapping tools, a bright soliton with center wavelength at $1.50 \mu \mathrm{m}$, peak power $4 \mathrm{~W}$, pulse $35 \mathrm{fs}$ is input into the system via the input port. The coupling
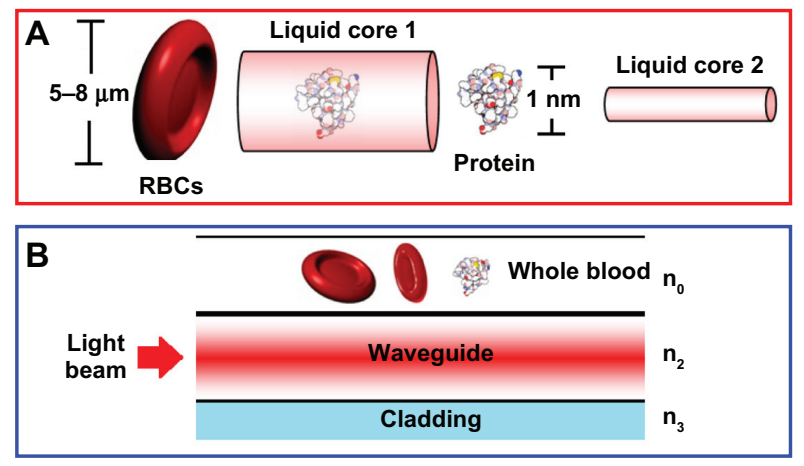

Figure 3 Schematic diagram of A) blood waveguide, B) blood waveguide structure. coefficients are given as $\kappa_{0}=0.5, \kappa_{1}=0.35, \kappa_{2}=0.1$, and $\kappa_{3}=0.35$, respectively. The ring radii are $\mathrm{R}_{\text {add }}=100$ and $75 \mu \mathrm{m}, \mathrm{R}_{\mathrm{R}}=40$ and $20 \mu \mathrm{m}$, and $\mathrm{R}_{\mathrm{L}}=40$ and $20 \mu \mathrm{m}$, respectively. To date, the evidence of a practical device with a radius of $30 \mathrm{~nm}$ has been reported by Tasakorn et al. ${ }^{31}$ $\mathrm{A}_{\text {eff }}$ are $300 \mu \mathrm{m}^{2}(\mathrm{r} \approx 9.77 \mu \mathrm{m})$ and $0.5 \mu \mathrm{m}^{2}(\mathrm{r} \approx 400 \mathrm{~nm})$. In this case, the dynamic tweezers (gradient fields) can be in the form of bright solitons, Gaussian pulses, and dark solitons for trapping the required blood waste. In Figure 4, there are four different center wavelengths of tweezers generated, where the dynamical movements are a) $\left.\left.\left|E_{1}\right|^{2}, b\right)\left|E_{2}\right|^{2}, c\right)\left|E_{3}\right|^{2}$, d) $\left.\left|E_{4}\right|^{2}, e\right)$ through port, and f) drop port signals. In this case, the trapped molecules (blood waste) are filtered and obtained by the drop port. For instance, by using a whole blood index (n) of 1.35, the trapping probe widths of $20 \mathrm{~nm}$ at the wavelength center at $1.60 \mu \mathrm{m}$ are generated (see Figure 4A). More results in terms of coupling constants are shown in Figure 4B, where in this case the tunable trapping can be obtained. In practice, the more reliable device (blood cleaner on-chip) fabrication parameters are the ring resonator radii instead of coupling constants. More results of the optical trapping probes generated within the PANDA ring with different wavelengths are as shown in Figure 5A; the bright soliton is used as the control signal for the tunable result. The output optical tweezers of the through and drop ports with different coupling constants are as shown in Figure 5B, which forms the basis for the selected blood waste molecules. In application, the clean blood can be transported into the human body via the through port. The filtering molecules (urine) are received 
A
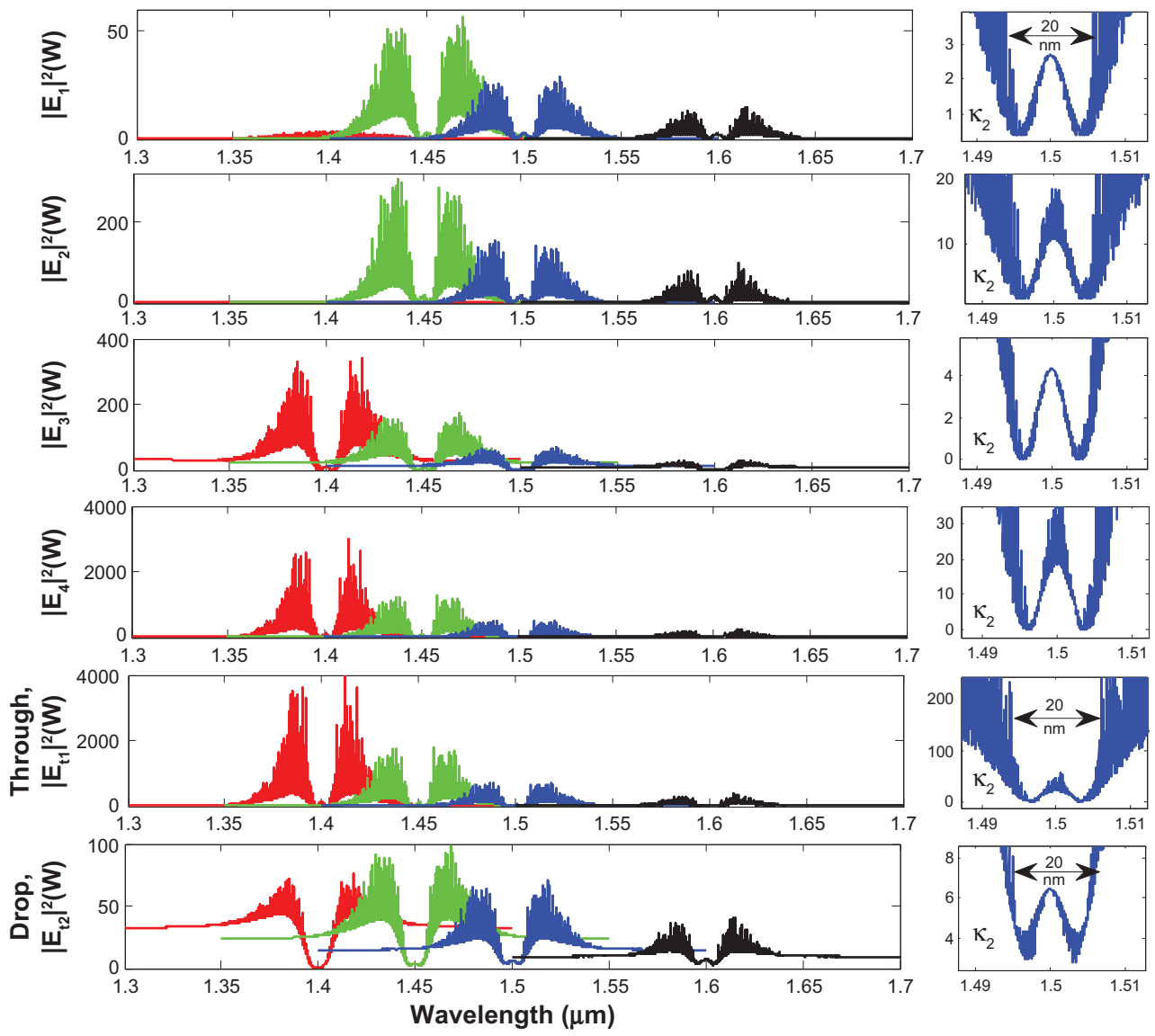

B
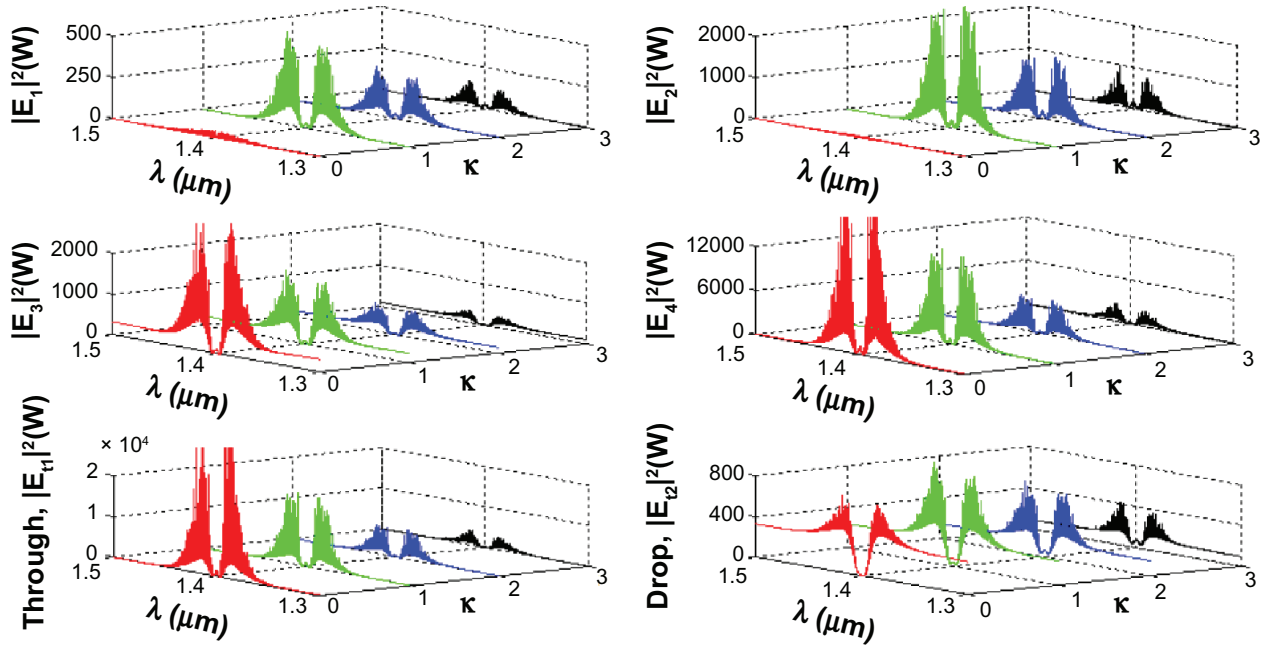

Figure 4 Results of the trapping tools with different $\mathbf{A}$ ) sizes and wavelengths, $\mathbf{B}$ ) tunable tweezers by coupling constant variation, where $R_{a d}=100 \mu m, R_{R}=R_{L}=40 \mu m$.

via the drop port. The advantage of the proposed system is that it can be fabricated on-chip and alternatively operated by a single device. ${ }^{57}$ The proposed system can be performed as a hemofiltration device, which is $90 \mu \mathrm{m}$ in depth, $200 \mu \mathrm{m}$ in width, and $300 \mu \mathrm{m}$ in length. The unwanted substances can be trapped (filtrated) by the optical gradient field, and can be delivered via the control port (different wavelengths). ${ }^{58}$ In operation, blood concentration does not affect the optical trapping ability, because the blood refractive index is slightly different, although it may affect the filtration speed. 
A
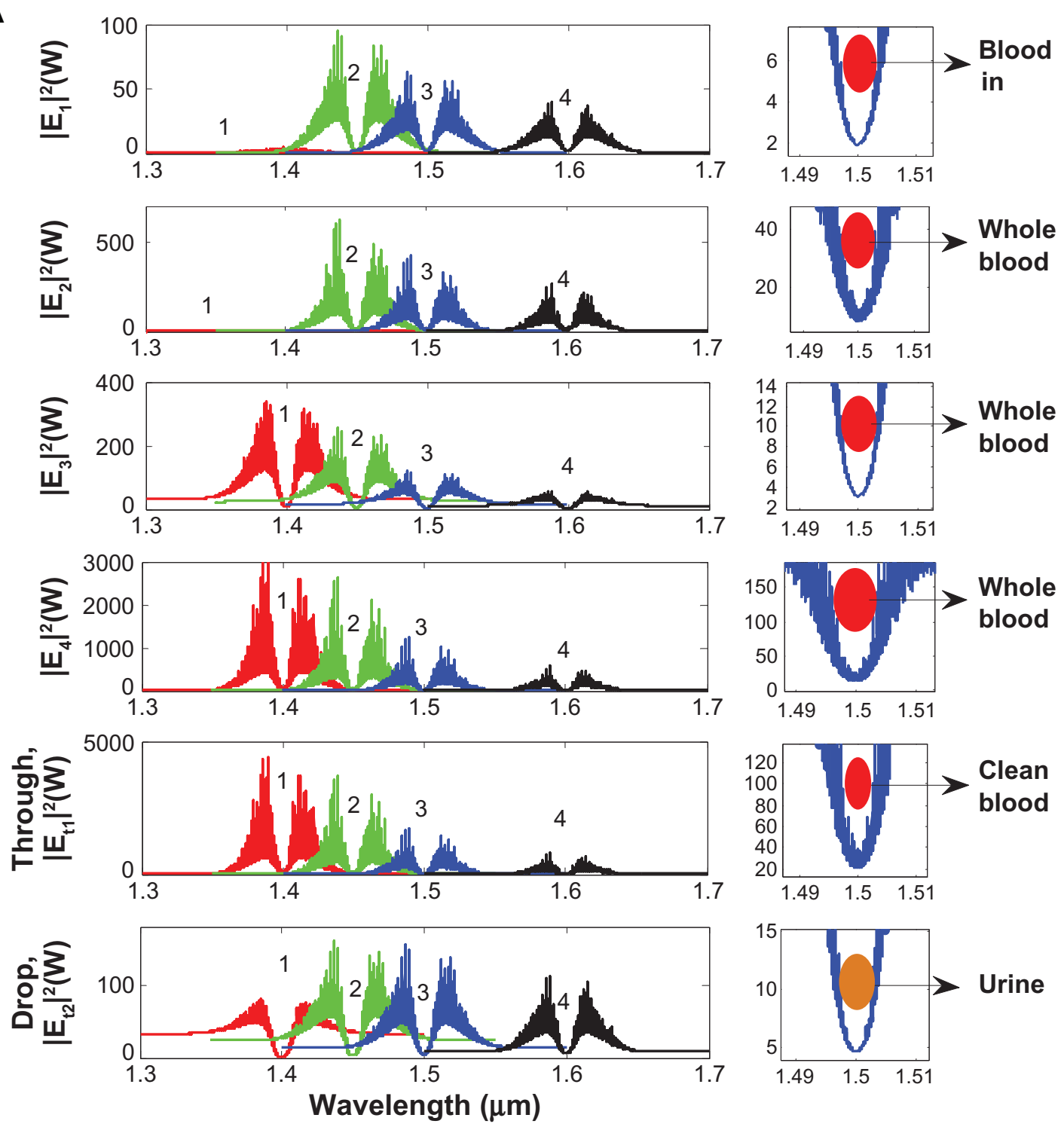

B
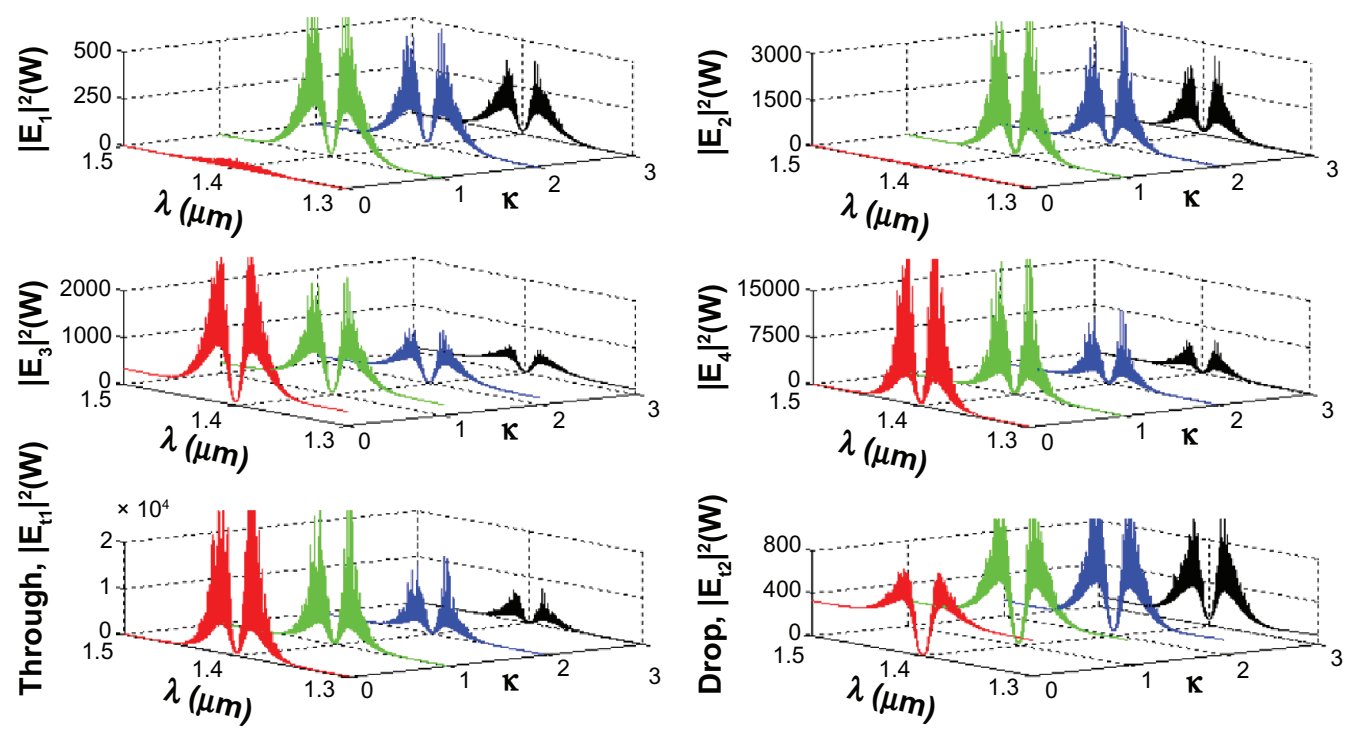

Figure 5 The optical tweezers with different $\mathbf{A}$ ) sizes and wavelengths, $\mathbf{B}$ ) tunable tweezers by coupling constant variation, where $R_{\text {add }}=75 \mu \mathrm{m}, R_{R}=R_{L}=20 \mu m$. 


\section{Conclusion}

We have shown that blood waste molecules can be trapped and filtered (transported) from the artificial blood cleaner (kidney), which can be performed on-chip. By utilizing the appropriate dark soliton input power, the required trapping tool sizes can be controlled and obtained, where finally the clean blood can be obtained before sending to the final destination (through port). Moreover, oxygen can be fed into the system via the control port, which is available for blood cleaning application. However, in practice, the blood cleaner on-chip system requires a specific environment, in which there are several sensors required to integrate into the system as shown in Figure 1, including bio-sensor, blood sensor, versatile sensor, protein sensor, and blood pressure sensor. Lastly, large molecules may be problematic for the generated trapping tool size. Therefore, the search for new media for guide pipes,${ }^{59}$ for instance, nano tube materials, and sensors, will be the next focus of investigation.

\section{Acknowledgments}

We would like to thank the Institute of Advanced Photonics Science, Nanotechnology Research Alliance, Universiti Teknologi Malaysia (UTM) and King Mongkut's Institute of Technology (KMITL), Thailand for providing the research facilities. This research work has been supported by UTM's Tier 1 Research Grant, MyBrain15 Fellowship, and the Ministry of Higher Education (MOHE) research grant.

\section{Disclosure}

No conflicts of interest were declared in relation to this paper.

\section{References}

1. Wesson LG. Physiology of human kidney. The Jefferson Medical College of Philadelphia. Pa. Grune and Stratton, Inc: New York; 1969.

2. McNamara BJ, Diouf B, Douglas-Denton RN, Hughson MD, Hoy WE, Bertram JF. Comparison of nephron number, glomerular volume and kidney weight in Senegalese Africans and African Americans. Nephrol Dial Transplant. 2010;25:1514-1520.

3. Manalich A, Reyes L, Herrera M, Melendi C, Fundora I. Relationship between weight at birth and the number and size of renal glomeruli in humans: a histomorphometric study. Kidney Int. 2000;58:770-777.

4. Rashad S, Barsoum MD. Chronic kidney disease in the developing world. N Engl J Med. 2006;354:997-999.

5. Scarpioni R, Ricardi M, Melfa L, Cristinelli L. Dyslipidemia in chronic kidney disease: are statins still indicated in reduction cardiovascular risk in patients on dialysis treatment. Cardiovasc Ther. 2010;28:361-368.

6. Coirault C, Pourny JC, Lambert F, Lecarpentier Y. Mechanical property analysis of stored red blood cell using optical tweezers. Med Sci. 2003;19: 364-367.

7. Grenier SR, Wei MT, Bai JJ, Chiou A. Dynamic deformation of red blood cell in dual-trap optical tweezers. Opt Express. 2010;18:10462-10472.

8. Nissenson AR, Ronco C, Pergamit G, Edelstein M, Watts R. Continuously functioning artificial nephron system: the promise of nanotechnology. Hemodial Int. 2005;9:210-217.
9. Locatelli F, Valderrabano F, Hoenich N, Bommer J, Leunissen K, Cambi V. Progress in dialysis technoloty: membrame selection and patient outcome. Nephrol Dial Transplant. 2000;15:1133-1139.

10. Gura V, Macy AS, Beizai M, Ezon C, Golper TA. Technical breakthroughs in the wearable artificial kidney. Clin J Am Soc Nephrol. 2009;4:1441-1448.

11. Forni LG, Hilton PJ. Continuous hemofiltration in the treatment of acute renal failure. N Engl J Med. 1997;336:1303-1339.

12. Bennie J, William P, Mather FW, inventors. Method for making artificial kidney. United States patent US 4211597. 1980 Jul 8.

13. Hardy MD, inventor. Implantable artificial kidney. United States patent US 5092886. 1992 Mar 3.

14. Fissell W, Fleischman AJ, Humes HD, Roy S. Development of continuous implantable renal replacement: past and future. Translational Res. 2007; 150:327-336.

15. Dykstra TM, inventor. Kidney dialysis method and device. United States patent US 5876366. 1999 Mar 2.

16. Ashkin A, Dziedzic JM, Yamane T. Observation of a single-beam gradient force optical trap for dielectric. Opt Lett. 1986;11:288-290.

17. Lu SJ, Feng Q, Park JS, et al. Biologic properties and enucleation of red blood cells from human embryonic stem cells. Blood. 2008;112: 4362-4363.

18. Chen HD, Ge K, Li Y, et al. Application of optical tweezers in the research of molecular interaction between lymphocyte function associated antigen-1 and its monoclonal antibody. Cell Mol Immunol. 2007;4: $221-225$.

19. Ashkin A, Dziedzic JM. Optical trapping and manipulation of viruses and bacteria. Science. 1987;235:1517-1520.

20. Zhao X, Sun Y, Bu J, Zhu S, Yuan XC. Microlens array enabled on-chip optical trapping and sorting. Applied Opt. 2011;50:318-322.

21. Lee WG, Park K, Bang H, et al. Single red blood cell defromnility test using optical trapping in plastic microfluid chip. Proceedings of the 31 Annual International IEEE EMBS Special Topic on Conference Microtechnologies in Medicine and Biology Kahuku, Oahu, Hawaii; 12-15 May 2005:389-390.

22. Obrist D, Weber B, Buck A, Jenny P. Red blood cell distribution in simplified capillary. Phil Trans R Soc A. 2010;368:2897-2918.

23. Chen YC, Chen GY, Lin YC, Wang GJ. A lab-on-a-chip capillary network for red blood cell hydrodynamics. Microfluid Nanofluid. 2010;9: 585-591.

24. Suwanpayak N, Jalil MA, Teeka T, Ali J, Yupapin PP. Optical vortices generated by a PANDA ring resonator for drug trapping and delivery applications. Bio Med Opt Express. 2011;2:159-168.

25. Piyatamrong B, Kulsirirat K, Techithdeera, Mitatha S, Yupapin PP. Dynamic potential well generation and control using double resonators incorporating in an add/drop filter. Mod Phys Lett B. 2010;24: 3071-3082.

26. Cai H, Poon A. Optical manipulation and transport of microparticle on silicon nitride microring resonator - based add-drop devices. Opt Lett. 2010;35:2855-2857.

27. Ashkin A, Dziedzic JM, Yamane T. Optical trapping and manipulation of single cells using infrared laser beams. Nature. 1987;330:769-771.

28. Egashira K, Terasaki A, Kondow T. Photon-trap spectroscopy applied to molecules adsorbed on a solid surface: probing with a standing wave versus a propagating wave. App Opt.1998;80:5113-5115.

29. Kachynski AV, Kuzmin AN, Pudavar HE, Kaputa DS, Cartwright AN, Prasad PN. Measurement of optical trapping forces by use of the two-photon-excited fluorescence of microspheres. Opt Lett. 2003;28: 2288-2290.

30. Schulz M, Crepaz H, Schmidt-Kaler F, Eschner J, Blatt R. Transfer of trapped atoms between two optical tweezer potentials. J Mod Opt. 2007;54:1619-1626.

31. Tasakorn M, Teeka C, Jomtarak R, Yupapin PP. Multitweezers generation control within a nanoring resonator system. Opt Eng. 2010;49: 075002 .

32. Svoboda K, Block SM. Biological applications of optical forces. Annu Rev Biophys Biomol Struct. 1994;23:247-283. 
33. Zhu J, Ozdemir SK, Xiao YF, et al. On-chip single nanoparticle detection and sizing by mode splitting in an ultrahigh- $Q$ microresonator. Nat Photonics. 2010;4:46-49.

34. Suwanpayak N, Yupapin PP. Molecular buffer using a PANDA ring resonator for drug delivery use. Int J Nanomed. 2011;6:575-580.

35. Psaltis D, Quake SR, Yang C. Developing optofluidic technology through the fusion of microfluidics and optics. Nature. 2006;442:381-386.

36. Yang AJH, Erickson D. Optofluidic ring resonator switch for optical particle transport. Lab Chip. 2010;10:769-774.

37. Chung AJ, Huh YS, Erickson D. A robust, electrochemically driven microwell drug delivery system for controlled vasopressin release. Biomed Microdevices. 2009;11:861-867.

38. Krishnan M, Tolley M, Lipson H, Erickson D. Hydrodynamically tunable affinities for fluidic assembly. Langmuir. 2009;25:3769-3744.

39. Chung AJ, Erickson D. Engineering insect flight metabolics using immature stage implanted microfluidics. Lab Chip. 2009;9:669-676.

40. Schmidt BS, Yang AHJ, Erickson D, Lipson M. Optofluidic trapping and transport on solid core waveguides within a microfluidic device. Optics Express. 2007;1:14322-14334.

41. Segev M, Christodoulides DN, Rotschild C, inventors. Method and system for manipulating fluid medium. United States patent US 2011/0023973A. 2011 Feb 3.

42. Bugge $M$, Palmers $G$, inventors. Implantable device for utilization of the hydraulic energy of the heart. United States patent US RE41,394E. 2010 Jun 22.

43. Chen SY, Hu SH, Liu DM, Kuo KT, inventors. Drug delivery nanodevice, its preparation method and used there of United States patent US 2011/0014296A1. 2011 Jan 20.

44. Yamamoto KI, Kobayashi K, Endo K, et al. Hollow-fiber blood-dialysis membranes: superoxide generation, permeation, and dismutation measured by chemiluminescence. J Artif Organs. 2005;8:257-262.

45. Huang HW, Ching Shih TC, Liauh CT. Predicting effects of blood flow rate and size of vessels in a vasculature on hyperthermia treatments using computer simulation. Bio Med Engin On Line. 2010;9:18.

46. Hudetz AG. Blood flow in the cerebral capillary network: a review emphasizing observations with intravital microscopy. Microcirculation. 1997;4:233-252.
47. Sardar DK, Levy LB. Optical properties of whole blood. Lasers Med Sci. 1998;13:106-111.

48. Bonanno LM, DeLouise LA. Whole blood optical biosensor. Biosens Bioelectron. 2007;23:444-448.

49. Harrison RV, Harel N, Panesar J, Mount RJ. Blood capillary distribution correlates with hemodynamic-based functional imaging in cerebral cortex. Cerebral Cortex. 2002;12:225-233.

50. Turkstra E, Braam B, Koomans HA. Impaired renal blood flow autoregulation in two-kidney, one-clip hypertensive rats is caused by enhanced activity of nitric oxide. J Am Soc Nephrol. 2000;11:847-855.

51. Thomson RJ, inventor. Blood concentrate detector. United States patent US 2009/0310123A1. 2009 Dec 17.

52. Carrara S. Nano-bio-technology and sensing chips: new systems for detection in personalized therapies and cell biology. Sensors. 2010;10: 526-543.

53. Preejith PV, Lim CS, Kishen A, John MS, Asundi A. Total protein measurement using a fiber-optic evanescent wave-based biosensor. Biotechnol Lett. 2003;25:105-110.

54. Das J, Kelley SO. Protein detection using arrayed microsensor chips: tuning sensor footprint to achieve ultrasensitive readout of CA-125 in serum and whole blood. Anal Chem. 2011;83:1167-1172.

55. Oyri K, Balasingham I, Samset E, Høgetveit JO, Fosse E. Wireless continuous arterial blood pressure monitoring during surgery: a pilot study. Anesth Analg. 2006;102:478-483.

56. Hsu TW, Chen YC, Wu MJ, Li AFY, Yang WC, Ng YY. Reinfusion of ascites during hemodialysis as a treatment of massive refractory ascites and acute renal failure. Int J Nephrol Renovasc Dis. 2001;4:29-33.

57. Santini JT, Richards AC, Scheidt R, Cima MJ, Langer R. Microchip as controlled drug delivery devices. Angew Chem Int Ed. 2000;39: 2396-2407.

58. Jesacher A, Maurer C, Furhapter S, Schwaighofer A, Bernet S, Ritsch-Marte M. Optical tweezers of programmable shape with transverse scattering forces. Opt Comm. 2008;281:2207-2212.

59. Ashkin A. Optical trapping and manipulation of neutral particles using lasers. Proc Natl Acad Sci U S A. 1997;94:4853-4860.
International Journal of Nanomedicine

\section{Publish your work in this journal}

The International Journal of Nanomedicine is an international, peerreviewed journal focusing on the application of nanotechnology in diagnostics, therapeutics, and drug delivery systems throughout the biomedical field. This journal is indexed on PubMed Central, MedLine, CAS, SciSearch $\AA$, Current Contents ${ }^{\circledR} /$ Clinical Medicine,

\section{Dovepress}

Journal Citation Reports/Science Edition, EMBase, Scopus and the Elsevier Bibliographic databases. The manuscript management system is completely online and includes a very quick and fair peer-review system, which is all easy to use. Visit http://www.dovepress.com/ testimonials.php to read real quotes from published authors. 